\title{
A Reflection on the Phenomenon of "argot "in linguistic view of landscape of Macao Shop
}

\author{
Lin Suzhen ${ }^{1, a}$, Qin Guiping ${ }^{2, b^{*}}$ \\ ${ }^{1}$ Ph.D.in International Chinese Language Education of Macau University of Science and Technology, Wai Lung Road, Tai Po, Macau, \\ China \\ ${ }^{2}$ Guangdong Polytechnic of Science and Trade, Shiqing Road, Guangzhou, Guangdong, China
}

\begin{abstract}
Absrtact: the landscape of Macao shops is first architectural symbol, which has the significance of design, then landscape symbol, which has geographical significance, and also public regional symbol, which has sociological significance. No matter which kind of symbol, in the final analysis, the essence is the collection of symbolic elements, first manifested as language symbols, then is the political, economic, cultural, educational and other multi-element word-formation, and finally affect its written writing style and communication mechanism is comprehensive and pluralistic. This paper expounds the phenomenon of "argot" in the language landscape of Macao shops from the aspects of folk culture, industry linkage and resource particularity, hoping to arouse more thinking about Macao's language landscape. It also hopes to provide some strategic thinking for changing the "single economic structure" mentioned in the outline.
\end{abstract}

\section{Page layout}

The Outline of the Guangdong-Hong Kong-Macau Greater Bay Area Development Plan (hereinafter referred to as "the Outline ") points out that" the development gap within the Dawan area is still large, the synergy and inclusiveness need to be strengthened, and the phenomenon of homogeneous competition and resource mismatch still exists in some regions and fields." ${ }^{[1]}$. Does the phenomenon of homogeneous competition and resource mismatch exist in the landscape of Macao shops, especially in the language of shops? Ideological culture is the soul of the country and nation, while landscape culture is the face of region and city, and the language symbol in landscape is the soul of landscape. This is the main purpose of this paper to investigate the Macao commodity language landscape.

From the perspective of sociolinguistics, this paper focuses on whether there is homogenization in the language landscape of shops in the Bay area, and whether homogenization causes a vicious circle of competition. From the point of view of current language communication and input mechanism, homogenization and resource mismatch are easy to confuse, mislead consumers and disturb market order. As a general collection of language symbols in public areas, the language landscape of the Bay area should first conform to the national common language and characters ${ }^{[2]}$ But it is actually designed in combination with the political, economic, cultural and other elements of its own region. As a public area, the primary role of shop language symbols is to express and transfer meaning, and then affect communication, so what kind of language

b34412667@qq.com landscape phenomenon will be caused by homogenization and resource mismatch?

The author investigates the main road shops in the Macao Peninsula, Taipa Island and Luhuan Island, taking the language symbols of the shops in Macao as the research object, focusing on the characters as the elements, and deeply analyzing the symbolic, systematic, hierarchical, social and ethnic characteristics of the language landscape. This paper focuses on Macao as a multilingual area, language has become a tool for communication and communication, and the language landscape of shops as a tool for communication and trading, is there only functional characteristics ${ }^{[3]}$ The author takes the shop of the main road of Macao as the object of investigation, and finds that it is far from enough to simply investigate the phonetic meaning of its characters and symbols, and there is a deep humanistic pulse behind it. So is there an industry "hermit "? So what is an industry cryptic? Jews who did business in the Middle Ages designed specific words to avoid the disclosure of key information, commonly known as "jargon ", while Jews who did business in modern times monopolized New York's jewelry processing industry also used" argot "to raise the threshold for non-Jews to enter the jewelry industry. ${ }^{[4]}$ The "argot" of the shop language landscape in this paper is similar to the "jargon" of the Jews. Besides its special function, it also has deep cultural, political and economic connotations ${ }^{[5]}$ or in the form of "hidden meaning "," metaphor "," recessive" and so on in the language landscape, with the characteristics of "obscure" or "hidden" characteristics. 


\section{The cultural nature of folklore leads to the industry's "argot"}

On 1 January 2018, Macao implemented the Prevention and Control of Smoking System, the Tobacco Control Act, No smoking in entertainment, Prohibit the public display of tobacco products at some outlets, Sales outlets such as convenience stores, supermarkets and street newspaper stalls in Macau can only show prices, Consumers can not see tobacco products through display windows outside the point of sale, It also stipulates that tobacco can not be advertised, This reduces the frequency of the word "tobacco" in the language landscape, I visited the shops in Macau, Find no more than 30 signboards from shops: Sichuan Tobacco Liquor, Chengxing Tobacco Co., Ltd., Lianyi Tobacco Co., Ltd., Phoenix Tobacco (Group) Co., Ltd., Macau Land Rolling Stock, Yunfu Rolling Stock (Macau) Co., Ltd., Macau Beauty Co., Ltd., Xingchang Tobacco Co., Ltd., Jincheng Tobacco Co., Ltd., Le Cesar, Fuyi Tobacco Co., Ltd., Yingfa Tobacco News, Macau Shanghai Rolling Stock Co., Ltd., Zhongxing Tobacco Co., Ltd., Hong Kong Tobacco Co., Ltd., Ltd., Yan Wanrong Tobacco Co., Ltd., International Wine, Hengchang Tobacco Wine Company, Changsheng Wine Company, Datong Bank, Chongqing Tobacco Company, Sanchang Tobacco Company, Sanchang Tobacco Company, Macau Hand letter, Fuchang Tobacco Company, Xinxinwei Tobacco Trade

Co., Ltd., Chengchang Tobacco Co., Ltd., "-Smoke" gradually withdrew from the Macao language landscape, On February 28,2021, Tencent changed its pseudo-language to " "(quit smoking), In the current context, The word "smoke" appears very low in the language landscape of shops, With the promotion of tobacco control law and the response of the public, Slowly the word "smoke" will withdraw from the field of language landscape.

For example, the Macao bus reminds passengers to beware of "pickpockets" and expresses "careful hands". Under the influence of" gentleman culture "and" villain culture "in traditional culture, the word" small hand "is more metaphorical than" pickpockets ". Hong Kong and Macao "hit the villain" custom still retains," small hand "and" villain "are deeply rooted in the hearts of citizens do not like behavior. Macau's shop language landscape can hardly be seen like the mainland shop "small XX" similar words, mainland shops will be nicknamed surname, such as" Xiao Lin Liang Tea Shop "and so on. The combination of "small" and surname is rare in the shop language landscape. In my field survey data, only the language elements combined with the region and animals, such as "small Chengdu", "small sweet (big lane)"," small animal medical clinic", "small expensive child "," small Shanghai restaurant", "small Shanghai private dish "," small heaven and earth (Father Luo street)"," small heaven and earth small white rabbit care center "," small heaven and earth children center "," small Winiduk center "," small Aidisheng health care center "," small sea swallow children "," small children "," small Andi school" and so on.It is rare to construct language landscape with morphemes of "younger age ", which is related to local humanistic psychology. ${ }^{[6]}$

The same old morpheme "old" is also taboo in the shop language landscape. The loving seat on the bus refers to the elderly, expressed as "elderly ", not" old "or" old ", influenced by Western taboo age culture. As a familiar morpheme ," old "is widely used. Once the morpheme involved in age is also in the state of" blanking ", the more scenes involving age morphemes in the mainland are also related to the traditional "modesty" culture. Instead of "blanking ", it appears as a more conspicuous scene, although the naming rules marking degree of the store language landscape are not high and have no characteristics. In addition to the recognition of their own products and the high self-recognition, the naming of the Chinese nation's 100 surnames and the same surnames is not conducive to communication and recognition. This is less common in Macao language landscape.

\section{Industry linkage causes industry "argot"}

Macao takes gambling industry as the economic pillar," pawnshop "and" gold shop "occupy the main share of the local economy. In Macao, the pawnshops are represented either by jewellery and watches, or by the word "profit" or "pledge ", which leads to the fact that the word" pawn "is almost hidden in the language landscape. They can only learn the function or marketing product of the store from the hidden words related to the word" pledge "or" profit ", but only from the "sound and meaning" of the language symbol of the store is unable to know the true intention of the language symbol to transmit information or express it $^{[7]}$

The author made statistics on the local watch line of Macao :" Ying Fu watch line "," Rong Mao watch line "," Enicar"(English Na GE handprint, note: Portuguese, Chinese style as the timer)," Timepieces", "Corum"(Kunyu handprint, German language, Chinese style as Gangyu ")," Moutblanc "[8], and(Hand in hand, Note: German, With time, MONT BLANC TO OOOIOVE WORD)," Great Shanghai Bridge "," Close Bridge "," Clock Mounting "," Time Gallery "," New Time Hand Shop "," New Times Clock Walk "," Chiba Table "," The Capital of the Table "," Sigma Timers", " Day Line "," Yuxinglong Watch "," Oriental Red Watch "," Cui Wenji Watch "," Famous Watch, Hope last letter)," eternal life line "," Patek Philippe Geneve", "Gmt·Time", " Da'an line "," time square line "," new light line "," Datong line "," Li Qiao record Zhong line "," Xiang Xing line "," big name line "," Song Yi line ", From the statistics, Chinese symbolic elements take "table line" as word-formation affixes to account for $4 / 5$, English "TIME" construction of language landscape accounts for $1 / 8$, From the word "clock" or "watch" or "time"(time) to know the clock trading shop, could not get the extra information of "pawn" from the word.

The term "pawn" is used as a trade term, For example ," God's bow "," God's mercy "," prosperity "," prosperity "," wealth "," gold "," wealth "," everlasting 
"," new Yongli "," God's money "," Jiangnan pawn "," God Fu "," profit "," Shun "," gold ""Administering "," Betting all wealth "," Betting all wealth "," Betting all fortune "," Betting all wealth "," Betting all fortune "," Betting all fortune "," Betting all fortune "," Betting all fortune "," Betting all fortune "," Betting all fortune "," Betting all fortune "," Betting all profits "," Betting city "," Betting all profits "," Betting all profits "," Betting all profits ", etc. The word "pawn" has only appeared in the south of the Yangtze River. Under the influence of gambling culture and folk culture, the words "hair "," rich "," wealth "," glory "," surplus "," Shun "," Xing "," win "," God "," blessing "," you "," Sheng "," victory "," benefit" and other morphemes are used as the elements of the word formation, and the psychological elements such as "seeking to win, seeking victory, praying for blessing and praying for the protection of gods" are used to form words to cater to the lucky psychology of the gamblers.

The word "pledge" is relatively simple to see the meaning of "pledge ", supplemented by" Fu Lu Shou Cai "in Chinese traditional folk culture, especially with the words" Fu, Shou, Cai ", and influenced by the pronunciation of Cantonese dialects. From the gambling industry to the pawn industry, the clock industry and the jewelry industry, the industry "argot ", from the industry to the linkage industry, The emergence of" argot "in the industry is a signifier with strong economic strength and cultural genes. This is a little different from a series of industrial linkage in the mainland, and the phenomenon of "argot" in the industry is rarely the external cause of the industry. But the industry itself is limited by the industry can not form tension or should not expand the dissemination of "argot ", difficult to have" linkage effect ". The phenomenon of "argot" caused by industrial linkage in the mainland is basically related to taboo words. For example, the "funeral" industry does not express on shop signs, but is replaced by the metaphor of "argot".

\section{The particularity of resources leads to "argot"}

The naming of "pawnshop" in Macao language landscape is a great spectacle and representative. The naming of jewelry products is also special in the Macao language landscape, especially in that some shops are both pawnbrokers and jewelry traders, and the naming of their main jewelry transactions forms a word with the word "Zhou ", such as" Zhou Sang-sheng "," Zhou Dafu "and" Saturday Fu ". On this basis, the mainland also has "Zhou Baifu "," Zhou Jinsheng "," Zhou Dafa" and so on. This section is to discuss because of the particularity of the industry and the scarcity of resources, there are only three "artificial" naming words in the language landscape of Macao shops, such as "Lianfa artificial Flower Factory Co., Ltd."," Venice everyone makes the sky "," Green Grass artificial first decoration company ", among which" artificial jewelry "is rare in the mainland, but still" express "in the language landscape. This phenomenon is taboo in the consumer market of mainland jewelry industry, because the psychological expectation of mainland market consumers can not accept jewelry doping or simulation. Even if they are artificial jewelry and jewelry, they avoid the word "artificial" and replace it with the word "simulation. Although the word "artificial" in the Macao language landscape has only one word-formation with the jewelry or jewelry industry, it just illustrates the more objective and factual feedback of the local product quality, although the Macao Trademark Registration — Macao Trademark Law ${ }^{[9]}$ Article 7 the form and content of the express product in "manufacturer or manufacturer to indicate its industrial product or manufactured product" shall be consistent, but the language symbol of the commodity landscape does not conceal the word "artificial ". This phenomenon of language landscape word formation not only shows the approachable nature of the law, but also shows that the local consumer's psychological expectation is also approachable, both of which have enough confidence to firmly believe in the corresponding market of the product.

The author examines the local language landscape of Guangzhou, The word "artificial" has been found to be a word-formation element in the main stone, wood, leather, lawn, plant and other industries such as "Yongya Meishe artificial stone special-shaped manufacturing center "," Shangxing wood-based panel Co., Ltd."," Baofeng artificial leather co., Ltd."," Shenzhen creative artificial stone co."," Guangzhou Feng grass artificial lawn co., Ltd."," artificial sea water miniature landscape "," Guangzhou Dongjun artificial plant co., Ltd."," Guangzhou Green Tan artificial lawn co."," Zengcheng artificial beach "," Yongfeng artificial board factory "," Guangzhou Dafeng artificial grass co., Ltd." Guangzhou Aosheng artificial grass limited public Division "," artificial football field "," Hengchun Garden artificial lawn" and so on, the word "artificial" and jewelry industry to form a language landscape phenomenon is almost zero, on the one hand, the local consumer's lack of self-confidence in consumer products, on the other hand, consumers to jewelry artificial wait-and-see attitude.

From the above point of view, Macao shop landscape is first architectural symbol, with design significance, followed by landscape symbol, with geographical significance, and public regional symbol, with sociological significance[10]No matter what kind of symbol, in the final analysis, the essence is the set of symbolic elements, first manifested as language symbols, then is the political, economic, cultural, educational and other multi-element word-formation, and finally affect its written writing style and communication mechanism is comprehensive and pluralistic. This paper expounds the phenomenon of "argot" in the language landscape of Macao shops from the aspects of folk culture, industry linkage and resource particularity, hoping to arouse more thinking about Macao's language landscape. It also hopes to provide some strategic thinking for changing the "single economic structure" mentioned in the outline. 


\section{Foundation project}

a practical study on the integration of traditional culture in Guangdong higher vocational characteristic teaching from the perspective of cultural self-confidence in the subject of education and teaching planning in the 13th Five-Year Plan of Guangdong Province as the soul and taking culture as the root 2016(item number: GXJK556)

\section{References:}

1. " Guangdong-Hong Kong-Macau Greater Bay Area Development Plan Outline "Announced_Xinhuanet http://www.xinhuanet.com/gangao/zt/ldzt/ldzter3/ind ex.htm

2. http://www.gov.cn/ziliao/flfg/2005-08/31/content_2 7920.htm [2] the National Common Language and Text Law of the People's Republic of China

3. A Study on Language Landscape in Beijing [M].] by $\mathrm{Xu}$ Ming Shanghai: Sanlian Bookstore, October 2020

4. Zheng Zining. Eastern and Western: Re-discovery of China [M].] in Language Gansu: Dunhuang Literature and Art Press, February 2020

5. Wu Kun. A Study on the Cultural Value of Urban Language Landscape [D].]1 Xihua University ,2017

6. Zheng Qianqian. A Comparative Study of Language Landscape in New and Old Commercial Circle of Guangzhou D]. China Jinan University ,2017

7. Wu Xi Li. A Review of Multilingual Phenomena in Language Landscape [J].] Study Journal of Guangzhou University (Social Sciences Edition),8th issue ,2017

8. Marlboron

https://baike.baidu.com/item/\%E4\%B8\%87\%E5\%A E\%9D\%E9\%BE\%99/1341303? Baidu Encyclopedia $\mathrm{fr}=$ aladdin

9. System http://legismac.safp.gov.mo/legismac/main/main.jsf? [9] Legal Information Enquiries lang $=\mathrm{zh} \_\mathrm{TW}$

10. Shan Feifei, Liu Chengyu. Research on Language Landscape of Ethnic Tourism Village _ Based on Social Semiotics and Cultural Capital Theory [J].].14 Ethnic Studies in Guangxi. 6 issue 